\title{
Estimation of Chlorophyll-a, TSM and Salinity in Mangrove Dominated Tropical Estuarine Areas of Hooghly River, North East Coast of Bay of Bengal, India Using Sentinel-3 Data
}

Ismail Mondal ( $\square$ ismailmondal58@gmail.com )

University of Calcutta https://orcid.org/0000-0002-1964-870X

Aakash De

University of Calcutta

Subhanil Nandi

University of Calcutta

Sandeep Thakur

University of Calcutta

Mini Raman

Space Application Centre (ISRO)

Tarun Kumar De

University of Calcutta

\section{Research Article}

Keywords: Sentinel-3, Chlorophyll-a, TSM, Hooghly estuary, Remote Sensing

Posted Date: January 17th, 2022

DOI: https://doi.org/10.21203/rs.3.rs-1191959/v2

License: (c) (i) This work is licensed under a Creative Commons Attribution 4.0 International License.

Read Full License 


\section{Abstract}

This study aims to explore the variations in spatio-temporal characteristics of water quality factors of three estuaries in the western portion of the Indian Sundarbans. Reliable retrieval of near surface concentrations of parameters such as Chlorophyll-a, SST \& TSM in various aquatic ecosystems with broad ranges of trophic needs has always remained a complex issue. In this study the application of C2RCC processor has been tested for its accuracy across different bio optical regimes in inland \& coastal waters. Satellite images for the same period were also collected and analysed using the C2RCC processing sequence to retrieve values of factors like the depth of water, surface reflectance, water temperature, inherent optical properties (IOPs), chlorophyll-a, salinity and total suspended matter (TSM) using the SNAP software. During the 2017-2020 season, in situ sampling from specific locations and laboratory water quality analysis were carried out. The $\mathrm{OLCl}$ retrieved results were then trained and corroborated by means of the in situ datasets. It was observed that the highest amount of TSM was recorded in Diamond Harbour during the pre-monsoon, in the year 2018 (301.40 $\mathrm{mgL}^{-1}$ in-situ value, and $308.54 \mathrm{mg} \mathrm{L}^{-1}$ estimated value). Similarly, chlorophyll-a had higher concentrations through the monsoon season (3.03 $\mathrm{mg} \mathrm{m}^{-3}$, in-situ, and $2.96 \mathrm{mg} \mathrm{m}^{-3}$, estimated) in Fraserganj and Sagar south points. Very good fitted correlation results for all seasons between Chl-a, $r=0.829$ and TSM, $r=0.924$ remained established throughout the comparisons of $\mathrm{OLCl}$ and in situ results. The high level of correlation highlights the importance of both primary as well as secondary information in understanding any dynamic system properly. Finally, the result shows that the water quality model outperforms conventional techniques and OLCl chl-a and TSM products. This paper empirically investigates a reliable remote sensing method for estimating coastal TSM and chl-a concentrations and supports the use of OLCl data in ocean colour remote sensing.

\section{Introduction}

The first satellite operation to assess coastal aquatic quality and ocean efficiency from a remote platform was the Coastal Zone Color Sensor (CZCS), which was propelled in October 1978 (Acker, J. 2013, Mondal et al., 2014; Kyryliuk, et al., 2019). This device has been utilized in approximating global production yield, and has steered our growing understanding of the importance of oceanic and littoral phytoplankton production (Longhurst et al., 1995; Behrenfeld et al., 2006). Chlorophyll-a is one of the typical water quality factors observed in aquatic bodies. It is measured by water sampling and laboratory analysis and through in situ measurements using a water quality checker. However, the CZCS has had difficulties in distinguishing between chlorophyll-a (Chl-a) and (TSM). Successive operations by the National Aeronautics and Space Administration (NASA) and the European Space Agency (ESA) have aimed to increase the accuracy of the retrieval of various water ingredients from space technology. The launch of OLCl (Ocean and land colour Instrument) on board the Sentinel 3A by the (ESA), in 2016 has enabled better management of the environment and to appreciate and improve data collection influenced by the effects of climate change (Donlon et al., 2014; Bonekamp et al., 2016; Mondal et al., 2019; 2020). OLCI 
mission is the follow up of the MERIS mission (2002-2012) (Pavel et al., 2011) with improved capabilities as its spectral conformation is premeditated for optically intricate coastal and inland aquatic bodies (Mondal et al., 2018; ESA, 2019; Kyryliuk, et al., 2019). Various studies have revealed that the OLCl is presently the most appropriate satellite instrument for water color remote sensing in inland aquatic bodies (Mograne et al., 2019; Xue et al., 2019).

The Hooghly estuary and its tributaries are an extraordinarily complex study object for ocean colour remote sensing. The very high amount of coloured dissolved organic matter (CDOM) received from the Sundarban mangrove forest in the catchment area along with anthropogenic inputs (Thakur et al., 2019) makes the water darker. As a result, the water loss signal is very small, necessitating the use of highly sensitive remote sensing devices as well as extremely precise atmospheric correction. In addition, due to fresh water input in the upper reaches and differential tidal influences, low salinity (psu) is common in some areas, while it is much higher in others. Similarly, there are stark differences in the TSM values along different stretches of the estuaries. This necessitates the need for a good algorithm to study the entire network of estuaries criss-crossing and crossing through the Indian Sundarbans. Eutrophication and hypoxia are regular phenomena in the Indian Sundarbans and, thus, environmentalists have been working to decrease the environmental pollution of runoff. Monitoring of chlorophyll concentrations is a very imperative contribution to evaluating these endeavours. Similar conditions have been stated in the OLCl images, with very good accuracy.

Most of the studies employing the OLCl images have been taken up in Europe and South East Asia. Studies along the eastern coast of India are very limited and, although the Sundarbans is one of the most studied areas in the world, no study using OLCl images has been attempted yet. Because of the fragility of water and the need for continuous monitoring, there is a need for real-time, surface-based studies of water quality parameters. However, due to accessibility and other logistics, that target has not been achieved on a regular basis. This study is an attempt to bridge the gap by using OLCl images from the Sentinel-3 to study a select few parameters of the Hooghly, Saptamukhi and Muri Ganga estuaries.

In this research, we presented a novel empirical model for estimating TSM and Chl-a concentrations in the Sundarban coastal waters of the Hooghly Estuary by integrating OLCl data with in situ data. Finally, the model was run using the time-series Sentinel-3 data to chart the spatial dispersal of TSM and Chl-a concentrations, and then the geographical and temporal distribution features of Chl-a concentration in the Sundarban coastal deltaic waters were analyzed. The main objectives of the study are- to estimate water quality factors such as salinity, surface temperature, chlorophyll-a concentration, and TSM concentration through seasonal field surveys (in-situ data); to use Sentinel-3 OLCl images in estimating salinity, surface temperature, chlorophyll-a concentration, and TSM concentration during 2017-19 by C2RCC processor \& to validate the results obtained by the OLCl estimations with the in situ data sets through regression equations.

\section{Materials And Methods}




\subsection{Study area}

The study area is part of the Sundarbans delta extending from $21^{\circ} 20^{\prime} \mathrm{N}$ to $22^{\circ} 40^{\prime} \mathrm{N}$ and $87^{\circ} 0^{\prime} \mathrm{E}$ to $89^{\circ} 0^{\prime} \mathrm{E}$ (Fig. 1) and is crisscrossed by many estuaries which are mostly distributaries of the Hooghly estuary (Thakur et al, 2020ab; Mondal, et al., 2016; 2021b; Bag et al., 2019; Bandyopadhyay et al., 2014). The delta is an ecologically delicate area that is stuck by consistent tidal ebb and flow of 12 durations each (Mondal et al., 2021a). The samples of water were collected at nine widely dispersed sampling stations along the mangrove-dominated banks of the Mooriganga, Saptamukhi, and Hooghly estuaries, three distributaries of the Ganges. The names of the stations are mentioned in table 1. A mapdisplaying the sampling stations along with specific geographical positions has been shown in figure 1 .

The region has a monsoonal climate with three main seasons, viz., pre-monsoon, monsoon and postmonsoon. Seasonal field observations were conducted at all the nine sampling stations throughout the monsoon season (July-Oct), the post-monsoon season (November-January), and the pre-monsoon seasons (March-June) for a period of two years, from November 2017 to January 2020.

Table 1: Name of sampling stations from North to south

\begin{tabular}{|c|c|c|c|c|}
\hline SI No & Station Name & Latitude & Longitude & Estuary \\
\hline 1 & BabuGhat & 88.286329 & 22.570876 & Hooghly \\
\hline 2 & Diamond Harbour & 88.266451 & 22.109261 & Hooghly \\
\hline 3 & Kachubaria Ghat & 88.27585 & 21.762018 & Hooghly \\
\hline 4 & Beguakhali Village & 88.243013 & 21.497898 & Hooghly \\
\hline 5 & Sagar South & 88.289175 & 21.451261 & Hooghly \\
\hline 6 & Namkhana & 88.370176 & 21.644417 & Sapatamukhi \\
\hline 7 & Fraserganj & 88.40682 & 21.443597 & Sapatamukhi \\
\hline 8 & Henry & 88.455004 & 21.437648 & Sapatamukhi \\
\hline 9 & Bakkhali & 88.444891 & 21.418613 & Sapatamukhi \\
\hline
\end{tabular}

\subsection{Data and Methodology}

\subsubsection{In situ data measurement and procedures}

The all in-situ samples of water were collected from the above mentioned stations and later analysed in the Marine science laboratory.

\subsubsection{In-situ water sample collection}

During this study, in situ biogeochemical data from nine sampling stations spanning a period of 2 years (2017-2019) was used. These stations are unique ecosystems, including coastal estuaries with varying 
degrees of tidal influences and human activities. The Sentinel-3 satellite passed above the selected sampling area around 09.32 am IST and water sample collection was carried out on 13.06.2018 \& 19.06.2019 for the monsoon, 13.12.2017, 10.12.2018 \& 2.01.2019 for the post-monsoon, and 21.04.2018 \& 24.04.2019 for the pre-monsoon. All waterbody samples were collected using clean plastic buckets from the middle portion of the river using mechanized boats. Both field data and satellite data were collected on the matching day and at the similar time (9.32 a.m. IST $\pm 30 \mathrm{~min}$ ), irrespective of the tidal conditions in the estuary. Collected water samples were kept in acid cleaned dry polythene bottles and transported to the laboratory for the measurement of suspended particulate matter and salinity. The temperature of surface water was measured at each station using a hand-held thermometer. The transparency was measured using a metal Secchi disc of $20 \mathrm{~cm}$ in diameter. The mean of three Secchi disc depths was chosen as the water transparency at each location (Preisendorfer 1986; Lee et al. 2015). All samples were delivered to the laboratory as soon as they were collected. Every time, triplicate samples were collected and analysed periodically to check the reproducibility of results and to evaluate the precision of measurements. Salinity was measured by argentometric iteration following the MohrKnudsen method (Grasshoff et al. 1983). TSM was separated by filtering an aliquot of water sample (1-2 litters) through a pre-weighed $0.45(\mathrm{~mm})$ Millipore membrane filter under vacuum, and weighing it with an accuracy of $(0 \pm 0.1 \mathrm{mg})$ after drying at $60^{\circ} \mathrm{C}$ or in desiccators in the presence of Conc. $\mathrm{H}_{2} \mathrm{SO}_{4}$.

\subsubsection{Estimation of Salinity and Temperature}

Salinity was estimated through the argentometric titration method, following Strickland \& Parsons, 1972. Samples of waste-water $(15 \mathrm{ml})$ were titrated against a standard $\mathrm{AgNO}_{3}$ solution, using a $\mathrm{K}_{2} \mathrm{CrO}_{4}$ solution $\left(3.5 \mathrm{~g} \mathrm{l}^{-1}\right)$ as an indicator. Silver nitrate solution was previously standardized against standard seawater solution ( $3.5 \mathrm{~g} \mathrm{NaCl}$ in $96.5 \mathrm{ml}$ distilled water), having chlorinity $19.375 \mathrm{ppt}$ and salinity $35 \%$ o. The salinity and chlorinity were related by Knudsen's equation; $\mathrm{S} \% \mathrm{o}=0.03+1.805 \mathrm{Cl} \%$. This technique is precise up to 0.05 to $0.1 \%$ of salinity. The water temperature was recorded during each sample collection using a laboratory thermometer.

\subsubsection{Chlorophyll measurement}

For the validation of water parameters, we collected around 15-20 cm under the river surface using Niskin bottles, and samples have been moved to the laboratory for further analysis. Water samples were clarified over $0.7 \mathrm{~mm}$ Whatman glass fiber filter (GF/F) paper under low vacuum and kept in acetone of $90 \%$ concentration at $0^{\circ} \mathrm{C}$ for $24 \mathrm{~h}$ in the dark for the complete extraction. The extracted solution was centrifuged at $10000 \mathrm{rpm}$ for $10 \mathrm{~min}$ and the solvent was used to estimate Chl-a concentration using a Shimadzu UV-vis 2450 spectrophotometer after the technique described in Strickland and Parsons (1972). The precision of Chl-a estimation is at the $5 \mu \mathrm{G}$ level, the correct value lies in the range:

Mean of $n$ determinations $\pm 0.26 / n^{1 / 2} \mu \mathrm{g}$ Chl-a

\subsubsection{TSM measurement}


The organic and inorganic section of (TSM in $\left.\mathrm{mg} \mathrm{L}^{-1}\right)$ has been quantified using the gravimetric technique meticulously given by Toming (2017) and also the MERIS protocols. Whatman Glass Fiber Filters (GF/F) are washed with ultrapure water to remove any drop filter bits, and they now combust at $4800 \mathrm{C}$ with an instruction to burn off any conceivable organic contamination (Doerffer et al., 2002). The weighted clean filters and they are kept in a folded square of aluminum foil paper $(0.020 * 100 * 100 \mathrm{~mm})$ through counted numbers up to their percolation. In accumulation, the amount of water samples $(1-2 L)$ has been filtered in triplicates over and done with the pre-weighed and also pre-combusted filter methods (Kratzer et al., 2018). The funnel and filter wash the clean water, then add $50 \mathrm{~mL}$ of ultrapure water to take out any residual salt. The filters were dried up overnight at $60^{\circ} \mathrm{C}$ and preserved in a desiccator prior to consideration by a microbalance $( \pm 1 \mu \mathrm{g})$. TSM was obtained through the dissimilation of both the tare and the dry weight. Then, the sample data is combusted at $480^{\circ} \mathrm{C}$ in an incinerator, monitored by an alternative weighing stage. The mass of the inorganic TSM was then equal to the mass of the combusted filters (modified tare weight), and the organic segment was the variance of the entire and the inorganic TSM.

\subsubsection{Sentinel-3 Satellite data processing}

\subsubsection{Image pre-processing}

The Sentinel-3 OLCI has a specification sensor as per its precursor Medium Resolution Imaging Spectrometer (MERIS) on ENVISAT with the capability to achieve an analysis of bio-optical ingredients in global coastal and inland regions (Doerer et al., 1999, Moore et al., 1999; Merheim-Kealy et al., 1999). The Sentinel-3 OLCI bands (Table 2) are an inheritance of MERIS and are supplemented to improve the quality of the measurement of ocean colour remote sensing. The Sentinel $3 \mathrm{OLCl}$ instrument swath area covers around $1270 \mathrm{~km}$ and it's tilted across by a track of 2.6 in the opposite track to the sun's angle in direction to minimize the potential effect of sun glint (ESA, 2019). Cloud free images for the period 2017-2020, viz. the monsoon (June), post-monsoon (November), and pre-monsoon (April) were downloaded and used in the study. The Sentinel-3 satellite passed above the selected sampling area around 9.32 am and satellite images with a \pm 6 -hour time lag from water sampling timings were collected on the following dates: 13.06.2018 \& 19.06.2019 for the monsoon, 13.12.2017, 10.12.2018 \& 2.01.2019 for the post-monsoon, and 21.04.2018 \& 24.04.2019 for the pre-monsoon. Using the SNAP software, the images were corrected for atmospheric effects. The Case-2 Regional/coast colour (C2RCC) processor was used for atmospheric correction (Brockmann et al., 2016). The C2RCC processor is a processing chain that helps in recovering water quality factors such as Chl-a, TSM, SST and salinity. The processor comprises of two neural nets. One net removes atmospheric and water surface effects (such as glint), while the other net retrieves absorption and scattering coefficients from which optically active substance concentrations (such as Chla) are calculated. The processor is available freely through the SNAP (Sentinel Application Platform) software. Finally, we have used the cloud-free pixel values relating to each sampling station's location were extracted from each thematic layer and verified against ground truth data. The extraction multi-layer values to points tool in Arc GIS was used to extract the Chl-a and TSM indices from the images at locations specified in a point feature class. For each input raster cluster value, a novel arena comprising 
the cell values for individual input raster is added to the input particular point feature class, and each pixel that covered the geographic location of the station value is extracted. After that, an attribute table was disseminated to MS Excel to build a connection between both the radiometric values and in-situ Chla and TSM concentration, as well as an analysis of the models produced. Figure 2 shows a summary of the methods used in this study.

\subsubsection{Methods}

The water pixels are processed exclusively by the Sentinel $3 \mathrm{OLCl}$ data processing system. A part of it is based on atmospheric correction, which produces water-leaving reflectance's and, as a by-product, the aerosol weight overhead it, and the other part is based on ocean colour processing, which is the derivation of the colour of the aquatic body itself from the water-leaving reflectance's of the suite of merchandises telling it.

Table 2: OLCI bands with MERIS heritage bands and additional highlighted in bold (source: ESA)

\begin{tabular}{|c|c|c|l|}
\hline $\begin{array}{c}\text { Band } \\
\text { Number }\end{array}$ & $\begin{array}{c}\text { Central } \\
\text { Wavelength } \\
\text { (nm) }\end{array}$ & $\begin{array}{c}\text { Bandwidth } \\
(\mathbf{n m})\end{array}$ & \multicolumn{1}{|c|}{ Function } \\
\hline Oa1 & 400 & 15 & AC, improved water constituent retrieval \\
\hline Oa2 & 412.5 & 10 & CDOM and detrital pigments \\
\hline Oa3 & 442.5 & 10 & Chl absorption maximum \\
\hline Oa4 & $\mathbf{4 9 0}$ & 10 & High Chl and other photosynthetic pigments \\
\hline Oa5 & 510 & 10 & Chl, TSM, turbidity and red tides \\
\hline Oa6 & 560 & 10 & Chl reference (minimum) \\
\hline Oa7 & 620 & 10 & TSM \\
\hline Oa8 & 665 & 10 & Chl (2nd absorption maximum), TSM and CDOM \\
\hline Oa9 & 673.75 & 7.5 & Improved fluorescence retrieval \\
\hline Oa10 & 681.25 & 7.5 & Chl fluorescence peak \\
\hline Oa11 & 708.75 & 10 & Chl fluorescence baseline \\
\hline Oa12 & 753.75 & 7.5 & $\mathrm{O}_{2}$ (oxygen) absorption and clouds \\
\hline Oa13 & 761.25 & 2.5 & $\mathrm{O}_{2}$ absorption band and AC aerosol estimation \\
\hline Oa14 & 764.375 & 3.75 & AC \\
\hline Oa15 & 767.5 & 2.5 & $\begin{array}{l}\mathrm{O}_{2} \text { A-band absorption band used for cloud top } \\
\text { pressure }\end{array}$ \\
\hline Oa16 & 778.75 & 15 & AC aerosol estimation \\
\hline Oa17 & 865 & 20 & $\begin{array}{l}\text { AC aerosol estimation, clouds and pixel co- } \\
\text { registration, in common with SLSTR }\end{array}$ \\
\hline Oa18 & 885 & 10 & Water vapour absorption reference band \\
\hline Oa19 & 900 & 10 & Water vapour absorption \\
\hline Oa20 & 940 & 20 & Water vapour absorption, linked to AC \\
\hline Oa21 & 1020 & 40 & AC aerosol estimation \\
\hline & & &
\end{tabular}




\subsubsection{Data integration}

The results of the laboratory analysis were then arranged in a systematic manner. Cloud free OLCI C2RCC processed pixel values conforming to the sampling location points were extracted. These values of data sets giving chl-a, TSM, SST and Salinity were also added to the database (Table 1; Fig. 2).

\subsubsection{Statistical analysis}

The validation operations took place between 2017 and 2020 in the Hooghly estuary of the Bay of Bengal. In different seasons of the year, marine, coastal, and inland water bodies have been covered, including in situ measurements of parameters such as chlorophyll-a, TSM, salinity, and sea surface temperature. After the datasets were assembled in one database, they were subjected to statistical analysis, and finally, the OLCl retrieved data validated with the in situ results by applying regression and correlation analysis using Matlab software.

\section{Results}

The physico-chemical and biological feature of a flowing river system largely depend on the tidal impacts, the intensity of contribution from point and non-point sources contributing on both sides of the banks, and the anthropogenic activity in and around the riverine system. Thus, the variations of the studied components are ascribed to tidal variations, spatial variations, and seasonal and annual variations. In this research, we have estimated the water quality factors from Sentinel-3 images along with multi-seasonal in-situ field data and have tried to validate and analyse the findings.

\subsection{Variation of Sea Surface Salinity}

Salinity, being the primary differentiating characteristic between freshwater and seawater, has shown significant variation in our study zone. In all seasons, Babughat station has recorded the lowest values, while Henry's island has had the highest salinity values. During the monsoon season, salinity is at its lowest, and at its highest during the pre-monsoon season. During the monsoon, mean salinity varied from $0.25 \pm 0.07$ at Babughat to $21.28 \pm 3.08$ at Bakkhali with small lower values of $20.86 \pm 2.06$ at Henry's island and of $20.93 \pm 1.80$ at the Sagar south sampling points. Another major contributor to mean monsoonal mean salinity was Fraserganj with $20.55 \pm 2.55$. During post-monsoon highest salinity of $24.36 \pm 0.97$ was recorded at Henry's island and the lowest of $0.55 \pm 0.05$ at Babughat. Other major observations of higher post monsoonal salinity were Kachubaria Ghat with $15.07 \pm 3.66$, Sagar south with $23.76 \pm 2.60$, Namkhana with $20.41 \pm 1.82$, Bakkhali with $23.79 \pm 1.17$, and Fraserganj with $24.06 \pm$ 1.55. Babughat, being dominantly freshwater, also showed the lowest mean salinity of $0.61 \pm 0.41$ throughout the pre-monsoon period, whereas Henry's island showed the highest value of $27.89 \pm 0.61$ salinity. Other stations with higher salinity observed were Sagar south with $27.45 \pm 0.28$, Bakkhali with $27.16 \pm 0.33$, Fraserganj with $26.14 \pm 0.21$, and Namkhana with $25.87 \pm 0.35$. Though Diamond Harbour is a major point on the Hooghly River, being situated in the upstream region has comparatively lower levels of mean salinity in all seasons. The mean salinity observed here was about $1.18 \pm 0.45$ during the 
post-monsoon, $1.43 \pm 0.66$ during the pre-monsoon, and $0.78 \pm 0.60$ throughout the monsoon season (Fig. 3).

\subsection{Variation of Sea Surface Temperature}

Water temperatures are generally higher during the monsoon and pre-monsoon seasons than throughout the post-monsoon season. During the post-monsoon, mean water temperatures have varied from $19.97 \pm$ $3.32^{\circ} \mathrm{C}$ at BabuGhat to $24.43 \pm 0.25^{\circ} \mathrm{C}$ at Henry's island. During this season, mean water temperatures at other stations were $22.40 \pm 2.97^{\circ} \mathrm{C}$ at Diamond Harbour, $20.10 \pm 0.52^{\circ} \mathrm{C}$ at Sagar south, and $24.38 \pm$ $0.16^{\circ} \mathrm{C}$ at Bakkhali. During the monsoon, the same parameter has varied from $28.75 \pm 2.47^{\circ} \mathrm{C}$ at Kachubaria to $33.90 \pm 3.54^{\circ} \mathrm{C}$ at Diamond Harbour. The mean water temperatures at some other stations were $31.35 \pm 0.21^{\circ} \mathrm{C}$ at Beguakhali, $31.48 \pm 0.39^{\circ} \mathrm{C}$ at Fraserganj, and $31.50 \pm 0.57^{\circ} \mathrm{C}$ at Bakkhali. Summer has dominated the pre-monsoon, resulting in higher mean water temperature values at all sampling stations. In this season it varied between $34.65 \pm 0.64^{\circ} \mathrm{C}$ at Sagar south and $30.05 \pm 0.07^{\circ} \mathrm{C}$ at Beguakhali and Henry's island and $30.05 \pm 0.35^{\circ} \mathrm{C}$ at Bakkhali. In the same season, the mean water temperature at BabuGhat was $32.90 \pm 2.69^{\circ} \mathrm{C}$ and at Diamond Harbour it was $33.90 \pm 0.14^{\circ} \mathrm{C}$ (Fig. 4). A point to be mentioned is that the water temperature variation majorly depends on tidal circulation and the sample collection time. Hence, from its variation, no important conclusion can be drawn directly.

\subsection{Mapping Chl-a Concentration from the OLCI Images}

Chlorophyll content of water is an excellent indicator of biotic production in any aquatic system. In estuaries like Hooghly, chlorophyll-a concentrations significantly describe water circulation and dilution patterns. It is sometimes also an important indicator of anthropogenic input of nutrients into the nearshore areas. In our study, the monsoonal concentration of in-situ (field survey) Chl-a was lower than in the other two seasons. During the monsoon, the mean Chl-a concentration varied from $1.16 \pm 0.10 \mathrm{mg}$ $\mathrm{m}^{-3}$ at Henry's Island to $2.47 \pm 0.36 \mathrm{mg} \mathrm{m}^{-3}$ at Diamond Harbour. Among other stations, Namkhana had exhibited $1.42 \pm 0.16 \mathrm{mg} \mathrm{m}^{-3}$, Sagar south had exhibited $1.86 \pm 0.31 \mathrm{mg} \mathrm{m}^{-3}$, Babu Ghat had exhibited $1.72 \pm 0.68 \mathrm{mg} \mathrm{m}^{-3}$, Beguakhali had exhibited $1.73 \pm 0.22 \mathrm{mg} \mathrm{m}^{-3}$ and Bakkhali had exhibited $1.40 \pm 0.10$ $\mathrm{mg} \mathrm{m}^{-3}$ (Fig. 5). During the same season, the estimated (Sentinal-3) Chl-a values were lower than the insitu values. The estimated values varied from $0.68 \pm 0.03 \mathrm{mg} \mathrm{m}^{-3}$ at Namkhana to $1.47 \pm 0.29 \mathrm{mg} \mathrm{m}^{-3}$ at Fraserganj (Fig. 6a).

During post-monsoon the estimated Chl-a values were higher compared to the monsoon, with a highest of $1.96 \pm 0.80 \mathrm{mg} \mathrm{m}^{-3}$ at Sagar South and a lowest of $1.05 \pm 0.28 \mathrm{mg} \mathrm{m}^{-3}$ at Henry's Island. Other major contributors to the in-situ mean Chl-a concentration in the post-monsoon season were $1.13 \pm 0.05 \mathrm{mg} \mathrm{m}^{-3}$ at Babu Ghat, $1.22 \pm 0.27 \mathrm{mg} \mathrm{m}^{-3}$ at Diamond Harbour, $1.16 \pm 0.83 \mathrm{mg} \mathrm{m}^{-3}$ at Namkhna point, and $1.53 \pm$ $0.40 \mathrm{mg} \mathrm{m}^{-3}$ at Bakkhali point (Fig. 6b).

During the same season, the in-situ Chl-a levels were higher than the estimated levels. The in-situ Chl-a varied from $2.28 \pm 0.70 \mathrm{mg} \mathrm{m}^{-3}$ at Sagar South to $1.26 \pm 0.04 \mathrm{mg} \mathrm{m}^{-3}$ at Babu Ghat (Fig. 5) When 
compared to the other two seasons, pre-monsoon concentrations of in-situ Chl-a were highest. During the pre-monsoon, the mean in-situ Chl-a concentration has varied from $2.45 \pm 0.50 \mathrm{mg} \mathrm{m}^{-3}$ at Bakkhali to $1.23 \pm 0.14 \mathrm{mg} \mathrm{m}^{-3}$ at Namkhana. Higher mean in-situ Chl-a concentrations were also observed on Henry's Island, i.e. of $2.15 \pm 0.52 \mathrm{mg} \mathrm{m}^{-3}$, in Diamond Harbour, i.e. of $1.80 \pm 0.31 \mathrm{mg} \mathrm{m}^{-3}$, in Babu Ghat, i.e. of $1.72 \pm 0.14 \mathrm{mg} \mathrm{m}^{-3}$ and in Sagar South, i.e. of $2.07 \pm 0.24 \mathrm{mg} \mathrm{m}^{-3}$ in this season (Fig. 5).

Again, in the pre-monsoon season, the estimated Chl-a concentration was lower than the in-situ values. The highest estimated Chl-a concentration was recorded at Bakkhali, i.e. $1.82 \pm 0.44 \mathrm{mg} \mathrm{m}^{-3}$ and the lowest was at Namkhana, i.e. $0.80 \pm 0.16 \mathrm{mg} \mathrm{m}^{-3}$ in this season during $2018-19$ (Fig. $6 \mathrm{c}$ ). This trend of mean Chl-a concentration variation has indicated that as the river flows downstream towards the Bay of Bengal, the parameter gets diluted and so the productivity drops lower.

\subsection{Mapping of Total Suspended Matter (TSM) from the OLCI Images}

The weight of TSM is dependent upon a number of factors present in the water column, e.g. turbidity, chlorophyll concentration, waste water dilution, and tidal fluctuations. Because of massive anthropogenic inflows, the upstream parts of the Hooghly estuary have shown higher values. TSMs concern their Bay of Bengal ward counterparts, with Beguakhali as an exception during the post-monsoon and monsoon seasons. During the post-monsoon season, the mean weight of in-situ TSM was the highest, $129.24 \pm$ $27.08 \mathrm{mg} \mathrm{L}^{-1}$ at Diamond Harbour, and the lowest, $25.53 \pm 9.48 \mathrm{mg} \mathrm{L}^{-1}$ at Babu Ghat. Other major contributors to the post monsoonal mean weight of in-situ TSM were Namkhana with $57.97 \pm 23.01 \mathrm{mg}$ $\mathrm{L}^{-1}$, Kachubaria with $101.71 \pm 32 \mathrm{mg} \mathrm{L}^{-1}$, Henry's Island with $82.65 \pm 18.21 \mathrm{mg} \mathrm{L}^{-1}$ and Bakkhali with $69.87 \pm 25.44 \mathrm{mg} \mathrm{L}^{-1}$ (Fig. 7).

The estimated TSM was higher compared to the in-situ values for this season. The highest estimated TSM concentration was recorded at Diamond Harbour, i.e. $134.61 \pm 30.55 \mathrm{mg} \mathrm{L}^{-1}$ and the lowest was at Babu Ghat, i.e. $41.86 \pm 22.24 \mathrm{mg} \mathrm{L}^{-1}$ (Fig. 8a). During the pre-monsoon, the scenario changes. With a mean weight of estimated TSM of about $114.06 \pm 30.61 \mathrm{mg} \mathrm{L-1}$, Babu Ghat had exhibited the lowest and, with about $281 \pm 26.95 \mathrm{mg} \mathrm{L}-1$, Kachubaria had acquired the highest position. Among other upstream sampling stations, Diamond Harbour had exhibited $180.58 \pm 25.83 \mathrm{mg} \mathrm{L}^{-1}$ and Namkhana had exhibited $102.93 \pm 84.48 \mathrm{mg} \mathrm{L}^{-1}$. Among downstream points, Sagar south had exhibited $119.26 \pm 11.39 \mathrm{mg} \mathrm{L}^{-1}$ and Henry's Island had exhibited $179.99 \pm 18.68 \mathrm{mg} \mathrm{L}^{-1}$ (Fig. 8b). This season, the highest in-situ TSM was measured at Kachubaria (273.05 $28.35 \mathrm{mg} \mathrm{L}-1$ ) and the lowest at Babu Ghat (108.03 27.72 mg L-1) (Fig. 7).

During the monsoon period at Fraserganj, the highest mean weight of estimated TSM, i.e. $150.41 \pm 26.17$ $\mathrm{mg} \mathrm{L}^{-1}$ was observed, and at Babu Ghat, the lowest value of $26.30 \pm 2.49 \mathrm{mg} \mathrm{L}^{-1}$ was observed. Similar to this, the weight of in-situ TSM was also highest at Fraserganj, i.e. $148.96 \pm 25.36 \mathrm{mg} \mathrm{L}^{-1}$ and was lowest 
at Babu Ghat at $24.64 \pm 2.77 \mathrm{mg} \mathrm{L}^{-1}$. Among other downstream points, Kachubaria has exhibited a 76.35 $\pm 2.97 \mathrm{mg} \mathrm{L}^{-1}$ estimated and a $72.38 \pm 2.33 \mathrm{mg} \mathrm{L}^{-1}$ in-situ TSM concentration. Bakkhali had an in-situ TSM concentration of $130.526 .35 \mathrm{mg} \mathrm{L-1}$ and an estimated TSM concentration of $95.7544 .28 \mathrm{mg} \mathrm{L-1}$. Whereas among upstream points, Diamond Harbour has exhibited an $89.80 \pm 39.27 \mathrm{mg} \mathrm{L}^{-1}$ estimated and a $95.50 \pm 6.50 \mathrm{mg} \mathrm{L}^{-1}$ in-situ TSM concentration. Namkhana had an in-situ TSM concentration of $45.6314 .77 \mathrm{mg} \mathrm{L}-1$ and an estimated TSM concentration of $47.2011 .19 \mathrm{mg} \mathrm{L-1} \mathrm{(Fig.} \mathrm{7;} \mathrm{8c).}$

Though Beguakhali is a major point in the downstream part of the Hooghly estuary, it has been shown to have lower values of the mean weight of the in-situ and estimated TSM in all seasons. It has shown a weight of an estimated TSM of $64.79 \pm 19.19 \mathrm{mg} \mathrm{L}^{-1}$ during the post-monsoon, $136.49 \pm 27.82 \mathrm{mg} \mathrm{L}^{-}$ ${ }^{1}$ during the pre-monsoon, and $57.53 \pm 18.21 \mathrm{mg} \mathrm{L}^{-1}$ during the monsoons.

\subsection{Correlation between estimated in-situ field data and Sentinel-3 OLCl data}

Aside from the chlorophyll-a and TSM, statistical regression analysis of Sentinel-3 reflectance data is an experimental method for obtaining algorithms for the interpretation of blue ocean color and inland water bodies. For ease of understanding of statistical variations, we have abbreviated the chlorophyll-a and TSM data in the following way:

Sentinel-3 estimated chlorophyll concentration $-X_{C h l . a}$ Sentinel-3 estimated TSM amount $-X_{T S M}$, Field in-situ chlorophyll concentration $-\mathrm{Y}_{\mathrm{Chl}}$ a, Field in-situ TSM amount $-\mathrm{Y}_{\text {TSM }}$.

The figures, 9a \& 9b, represent the best-fitted line plots for both Chl-a and TSM. This plot was created using all of the season values. This indicates the significant linear association amongst the sentinel-3 data and field data. When studied for individual seasons, the regression equations are different. The values for chlorophyll-a were well distributed and represented the statistical variability. But for TSM, some biased readings towards the lower representatives were observed. This may be attributed to locationspecific biotic environmental interactions and pollution.

During pre-monsoon individual regression equations turned out as $Y_{\text {Chl.a }}=0.3548+1.042 X_{\text {Chl.a }}\left(R^{2}=\right.$ $0.823)$ and $Y_{T S M}=36.10+0.7905 X_{T S M}\left(R^{2}=0.866\right)$ for Chl- $a$ and TSM respectively. This scenario further changes during the monsoon season.

During the monsoon, the linear relationships were $\mathrm{Y}_{\text {Chl.a }}=0.5736+1.023 \mathrm{X}_{\mathrm{Chl.a}}\left(\mathrm{R}^{2}=0.613\right)$ and $\mathrm{Y}_{\mathrm{TSM}}=$ $28.94+0.7172 \mathrm{X}_{\mathrm{TSM}}\left(\mathrm{R}^{2}=0.628\right)$ for Chl- $a$ and TSM respectively.

But during post-monsoon the relationship normalizes and the equations turned out as $\mathrm{Y}_{\text {Chl.a }}=0.4900+$ $0.9300 \mathrm{X}_{\text {Chl.a }}\left(R^{2}=0.847\right)$ and $\mathrm{Y}_{\mathrm{TSM}}=10.79+0.7658 \mathrm{X}_{\mathrm{TSM}}\left(\mathrm{R}^{2}=0.774\right)$ Chl- $\mathrm{a}$ and TSM respectively. These inferential statistical analyses helped to determine that our acquired objective for comparing 
ground data and satellite data is significantly viable for larger populations and varied hydrological parameters. This could be bolstered further by a correlation study between the two.

Table 3. Table showing Seasonal correlation between Sentinel-3 observed data and field data of Chl-a and TSM

\begin{tabular}{|c|c|c|c|}
\hline Season & Parameter & r value & $\mathrm{p}$ value \\
\hline Monsoon & \multirow{3}{*}{$\mathrm{Y}_{\text {Chl.a }}$ vs. $\mathrm{X}_{\text {Chl.a }}$} & 0.619 & 0.006 \\
\hline Post Monsoon & & 0.920 & 0.000 \\
\hline Pre Monsoon & & 0.907 & 0.000 \\
\hline Monsoon & \multirow{3}{*}{$\mathrm{Y}_{\text {TSM }}$ vs. $\mathrm{X}_{\mathrm{TSM}}$} & 0.792 & 0.000 \\
\hline Post Monsoon & & 0.880 & 0.000 \\
\hline Pre Monsoon & & 0.931 & 0.000 \\
\hline
\end{tabular}

A significant correlation was observed between field data and Sentinel-3 data in all seasons along the Hooghly River for both parameters, i.e. Chl-a and TSM (Table 3). All $r$ values for individual seasons were > 0.5 , which indicates a significant relationship. This may further be supported by $p$ values, i.e. all values $\leq$ 0.05. This validates the level of accuracy of field sampling and also states the importance of both primary and secondary data in understanding any dynamic system properly. When studied for all seasons, for Chl-a, $r=0.829$ and $p=0.000$ and for TSM, $r=0.924$ and $p=0.000$. Both these were again significantly supported by the strength of satellite data and field data variables. Although there is a continuing argument amongst scholars about the reliability of primary field data versus secondary satellite data, this type of comparative study might work as a conduit between the two and will have a futuristic application of interpretation in oceanic research.

The study's findings indicate the need to develop an algorithm specific to the Hooghly estuary, particularly for the C2RCC processor, because the current ones only provide sensible reflectance outcomes in Chlorophyll and TSM circumstances and correlation with in-situ data.

\section{Discussion Of The Study}

In the present scenario, the spectral and temporal resolution of OLCI makes it ideal for mapping and collecting water quality parameter information for large-scale coastal waters. The OLCl data has been acquired nearly daily using the Sentinel-3A and Sentinel-3B satellites' ocean monitoring programme. However, image quality is constantly affected by the weather, particularly in cloudy and rainy subtropical coastal regions such as the Sundarban delta. This limits the usefulness of the OLCl images for studying 
ocean colour, yet this climatic factor is unavoidable in optical remote sensing. To acquire additional ocean colour information in the future, we should explore combining multi-source satellite data. Furthermore, the atmospheric adjustment is important for retrieving ocean colour. The quality of the atmospheric adjustment has a substantial effect on the remote sensing inversion outcome. For ocean colour modelling, a good atmospheric correction technique can provide high-quality reflectance data.

Despite the fact that ocean colour missions have given us with a plethora of ocean colour products, their suitability for use in local environments has not been determined. In this study, we compared the Chl-a and TSM with a correlation matrix-based model on in-situ measurement with the (IOPs) product. While the spatial distribution of TSM and Chl-a concentrations from various techniques is usually comparable, the TSM and Chl-a values from each method have vastly different ranges. The primary reason for this is that field measurement data for other ocean colour models has been gathered from different ocean areas throughout the years, while in-situ measurement data for the correlation matrix-based model is collected from the Hooghly estuary's coastal waters (Fig. 10). According to our result shows the Sentinel-3 products are suitable for ocean color monitoring in Hooghly estuary of Sundarban coastal waters. Although the correlation matrix-based technique has shown positive results in the coastal waters of the Hooghly estuary, for the spatial application of this method. Finally, our approach, on the other hand, offers significant reference value for the study of ocean colour in other coastal regions.

\section{Conclusions And Outlook}

The retrieval of the estuarine water quality parameters and its subsequent validation was generally successful with moderately consistent results (comparatively stumpy bias and scatter) for the Chl-a, TSM, salinity, and water temperature. In general, the C2RCC does well in recovering a remote sensing spectrum with a distinctive deltaic shape for estuary waters with a reflectance peak at $560 \mathrm{~nm}$. Results revealed that the maximum concentration of chlorophyll-a was observed during the post-monsoon period (2.96 $\mathrm{mg} \mathrm{m}^{-3}$, estimated and $3.17 \mathrm{mg} \mathrm{m}^{-3}$, in-situ) on Sagar Island South. The amount of chlorophyll-a belongs moderately in the continental shelf zone than continental slope because of the abundance of phytoplankton. That is why the continental shelf zone is better for fishing activities. The in-situ results total amount of TSM has decreased progressively into land towards the sea completely over the year (2017-2020). The amount of TSM is very low at the most upstream sampling point, i.e. Babu Ghat. It has shown a mean of $36.76 \mathrm{mg} \mathrm{L}^{-1}$ in-situ and $58.04 \mathrm{mg} \mathrm{L}^{-1}$ estimated TSM in all seasons of our study period. The study results have also shown the highest amount of in-situ TSM at Fraserganj during the monsoon time in 2019 (174.32 mgL-1), much more in the monsoon period than in the post-monsoon period in the Hooghly estuaries.

The intention of this study was to check the performance of Sentinel-3 OLCl in coastal waters by appraising the results of atmospherically corrected ocean colour products produced by a standard processor (C2RCC), and the results point to very good performance in the test. Very good fitted correlation results for all seasons between $\mathrm{Chl}-\mathrm{a}, \mathrm{r}=0.829$ and TSM, $r=0.924$ were obtained during the comparisons of OLCl with the in situ results. The high level of correlation highlights the importance of both primary and 
secondary data in understanding any dynamic system properly. This research could pave the way for future research into the estuarine waters of the Indian Sundarbans, which are difficult to access for laboratory-based studies. Real-time monitoring using OLCl images and the application of different algorithms could bring about a very good chance in the environmental monitoring programs of the Indian Sundarbans.

\section{Declarations}

Ethical Approval: Not applicable

Consent to Participate: Not applicable

Consent to Publish: Not applicable

\section{Authors Contributions:}

Ismail Mondal: Conceptualization, Writing- original draft, Software, Formal analysis, Visualization. Aakash De, Subhanil Nandi, Sandeep Thakur, Data curation, Formal analysis; Writingoriginal draft, Visualization. Mini Raman, and Tarun Kumar De: Writing, Review and editing, Supervision.

\section{Funding and Acknowledgment:}

The work has been done under the project entitled "Water quality assessment using AVIRIS-NG satellitederived data along the Hooghly (Ganges) River Estuary, Eastern part of India" [Reference No.:

A/F/693/4S-2973/2016] with collaboration between Space Applications Centre, ISRO, Ahmedabad, and the Department of Marine Science, University of Calcutta, Kolkata, India. The financial support from SAC, ISRO, Ahmedabad, is gratefully acknowledged. The help from the Port Trust Authority of India and Shipping Corporation of India is being duly and gratefully acknowledged for their support during the sampling periods by providing us with means of riverine transportation and personnel of assistance. Finally, the authors are indebted to the University Grants Commission, Government of India; for the award of the DS Kothari Post-Doctoral Fellowship (ES/20-21/0009) to Dr. Ismail Mondal. And also the European Space Agency (ESA) for providing the Sentinel-3 data to further extend our research work.

\section{Competing Interests:}

This manuscript has not been published or presented elsewhere in part or in entirety and is not under consideration by another journal. There are no conflicts of interest to declare.

\section{Availability of data and materials:}

The data that support the findings of this study are available from the author, [lsmail Mondal, ismailmondal58@gmail.com], upon reasonable request.

\section{Declarations:}


The authors declare that they have no known competing financial interests or personal relationships that could have appeared to influence the work reported in this paper.

\section{References}

Acker, J. How Two Sides of the Atlantic Contributed to Understanding of the Global Oceans: Charles Yentsch and Andre Morel. Limnol. Oceanogr. Bull. 2013, 22, 2-6.

Bag, R.; Mondal, I.; Bandyopadhyay, J. Assessing the oscillation of channel geometry and meander migration cardinality of Bhagirathi river, West Bengal, India. J.Geogr.Sci.2019, 29:1-22, DOI: https://doi.org/10.1007/s11442-019-0000-0.

Bandyopadhyay, J. Mondal, I and Samanta, N. Shore Line Shifting of Namkhana Island of Indian Sundarban, South 24 Parganas, West Bengal, India, Using Remote Sensing \&GIS Techniques. International Journal of Engineering Sciences \& Research Technology, 2014. 3(5):162-169.

Behrenfeld, M.J.; O’Malley, R.T.; Siegel, D.A.; McClain, C.R.; Sarmiento, J.L.; Feldman, G.C.; Milligan, A.J.; Falkowski, P.G.; Letelier, R.M.; Boss, E.S. Climate-driven trends in contemporary ocean productivity. Nature. $2006,444,752-755$.

Bonekamp, H.; Montagner, F.; Santacesaria, V.; Loddo, C.N.; Wannop, S. Core operational Sentinel-3 marine data product services as part of the Copernicus Space Component. Ocean Sci. 2016, 12, 787-795.

Doerer, R.; Sorensen, K.; Aiken, J. MERIS potential for coastal zone applications. Int. J. Remote Sens. 1999, 20, 1809-1818.

Doerffer, R. Protocols for the Validation of MERIS Water Products; European Space Agency Doc. No. POTN-MEL-GS-0043; GKSS: Geesthacht, Germany, 2002; pp. 1-42.

Donlon, C.; Berruti, B.; Buongiorno, A.; Ferreira, M.; Féménias, P.; Frerick, J.; Goryl, P.; Klein, U.; Laur, H.; Mavrocordatos, C.; et al. Remote Sensing of Environment the Global Monitoring for Environment and Security (GMES) Sentinel-3 mission. Remote Sens. Environ. 2014, 120, 37-57.

ESA Overview / Copernicus / Observing the Earth / Our Activities / ESA. Available online:http://www.esa.int/Our_Activities/Observing_the_Earth/Copernicus/Overview4 (accessed on 2 April 2019).

ESA Sentinel-3 - Missions - Sentinel Online. Available online: https://sentinel.esa.int/web/sentinel/missions/ sentinel-3 (accessed on 7 April 2019).

ESA User Guides - Sentinel-3 OLCl - Heritage - Sentinel Online. Available online: https://sentinel.esa.int/web/sentinel/user-guides/sentinel-3-olci/overview/heritage (accessed on 8 April 2019) 
Grasshoff, K., Ehrhardt, M., Kremling, K. (Eds.), 1983. Methods of Seawater Analysis, 2nd edn. Verlag Chemie, Weinheim, 317 pp.

Kratzer, S. Moore, G. Inherent Optical Properties of the Baltic Sea in Comparison to Other Seas and Oceans, Remote Sens. 2018, 10, 418; doi:10.3390/rs10030418

Kyryliuk, D. Kratzer, S. Evaluation of Sentinel-3A OLCI Products Derived Using the Case-2 Regional Coast Colour Processor over the Baltic Sea, Sensors 2019, 19, 3609; doi:10.3390/s19163609.

Lee, Z., J. Wei, K. Voss, M. Lewis, A. Bricaud, and Y. Huot. Hyperspectral absorption coefficient of "pure" seawater in the range of 350-550 nm inverted from remote sensing reflectance. Appl. Opt. 2015. 54: 546-558. doi:10.1364/ A0.54.000546

Longhurst, A.; Sathyendranath, S.; Platt, T.; Caverhill, C. An estimate of global primary production in the ocean from satellite radiometer data. J. Plankton Res. 1995, 17, 1245-1271.

Merheim-Kealy, P.; Huot, J.P.; Delwart, S. The MERIS ground segment. Int. J. Remote Sens. 1999, 20, 1703-1712.

Mondal, I, Bandyopadhyay, J. Coastal Zone Mapping through Geospatial Technology for Resource Management of Indian Sundarban, West Bengal, India, International Journal of Remote Sensing Applications, 2014. 4(2), 103-112 DOI: 10.14355/ijrsa.2014.0402.04

Mondal, I. Bandyopadhyay, J. Paul, AK. Water quality modeling for seasonal fluctuation of Ichamati River, West Bengal, India. Model Earth Syst. Environ. 2016 2:113, DOI: 10.1007/s40808-016-0153-3.

Mondal, I. Thakur, S. Ghosh, PB. De, T.K. Bandyopadhyay, J. Land Use/Land Cover Modeling of Sagar Island, India using Remote Sensing and GIS Techniques, Springer Advances in Intelligent Systems and Computing (AISC), Emerging Technologies in Data Mining and information

Security, 2018. 755, https://doi.org/10.1007/978-981-13-1951-8_69:771-785.

Mondal, I. Thakur, S. Bandyopadhyay, J. Delineating lateral channel migration and risk zones of Ichamati River, West Bengal, India, Journal of Cleaner Production, Elsevier, 2019.

244:118740, https://doi.org/10.1016/j.jclepro.2019.11874.

Mondal, I. Thakur, S. Juliev, M. Bandyopadhyay, J. De, TK. Spatio-temporal modelling of shoreline migration in Sagar Island, West Bengal, India, Journal of Coastal Conservation, Springer, 2020. 24:50.120 https://doi.org/10.1007/s11852-020-00768-2

Mondal, I., Thakur, S., Juliev, M., De, T.K. Comparative analysis of forest canopy mapping methods for Sundarban biosphere reserve, West Bengal, India. Environment Development \& Sustainability. 2021a. DOI: 10.1007/s10668-021-01291-6. 
Mondal, I. Thakur, S. Ghosh, PB. De, T.K. Assessing the Impacts of Global Sea Level Rise (SLR) on the Mangrove Forests of Indian Sundarbans Using Geospatial Technology, Geographic Information Science for Land Resource Management, Wiley, 2021b. 11: 209-228, 10.1002/9781119786375.ch11

Moore, G.F.; Aiken, J.; Lavender, S.J. The atmospheric correction of water colour and the quantitative retrieval of suspended particulate matter in Case II waters: Application to MERIS. Int. J. Remote Sens. $1999,20,1713-1733$.

Moses, W.J.; Gitelson, A.A.; Berdnikov, S.; Povaznyy, V. Estimation of chlorophyll-a concentration in case II waters using MODIS and MERIS data-Successes and challenges. Environ. Res. Lett. 2009, 4, 4.

Paavel, B.; Arst, H.; Metsamaa, L.; Toming, K.; Reinart, A. Optical investigations of CDOM-rich coastal waters in Parnu Bay. Estonian J. Earth Sci. 2011, 60, 102-112.

Preisendorfer, R.W., 1986. Secchi disk science: Visual optics of natural waters. Limnology and Oceanography, 3(5), 909-926.

Strickland, J.D. and Parsons, T.R. A Manual of Seawater Analysis. Fisheries Research Board Canada. 1972. $167 ; 310$.

Thakur, S. Maity, D. Mondal, I. Basumatary, G. Ghosh, PB. De, T.K. Assessment of changes in land use, land cover, and land surface temperature in the mangrove forest of Sundarbans, northeast coast of India, Environment, Development and Sustainability, 2020a. 22(3):1-29 https://doi.org/10.1007/s10668-02000656-7

Thakur, S., Mondal, I., Bar, S., Nandi, S., Das, P., Ghosh, P. B., et al. Shoreline changes and its impact on the mangrove ecosystems of some Islands of Indian Sundarbans, North- East coast of India. Journal of Cleaner Production, 2020b. Elsevier, 284, 124764. https://doi.org/10.1016/j.jclep ro.12476 4.

Thakur, S., Mondal, I., Ghosh, P. B., Das, P., \& De, T. K. A review of the application of multispectral remote sensing in the study of mangrove ecosystems with special emphasis on image processing techniques. 2019. Spatial Information Research. doi:10.1007/s41324-019-00268-y.

Toming, K. Kutser, T. Uiboupin, R. Arikas, A. Vahter, K. Paavel, B. Mapping Water Quality Parameters with Sentinel-3 Ocean and Land Colour Instrument Imagery in the Baltic Sea. Remote Sens. 2017, 9, 1070; doi:10.3390/rs910107.

Mograne, A.M., Jamet, C., Loisel, H., Vantrepotte, V., Meriaux, X., Cauvin, A., 2019. Evaluation of five atmospheric correction algorithms over French optically-complex waters for the sentinel-3A OLCl Ocean color sensor. Remote Sens. 11.

Xue, K., Ma, R., Duan, H., Shen, M., Boss, E., Cao, Z., 2019. Inversion of inherent optical properties in optically complex waters using sentinel-3A/OLCl images: a case study using China's three largest freshwater lakes. Remote Sens. Environ. 225, 328-346. 
Brockmann, C., Doerffer, R., Peters, M., Kerstin, S., Embacher, S., Ruescas, A., 2016. Evolution of the C2RCC Neural Network for Sentinel 2 and 3 for the Retrieval of Ocean Colour Products in Normal and Extreme Optically Complex Waters.

\section{Figures}

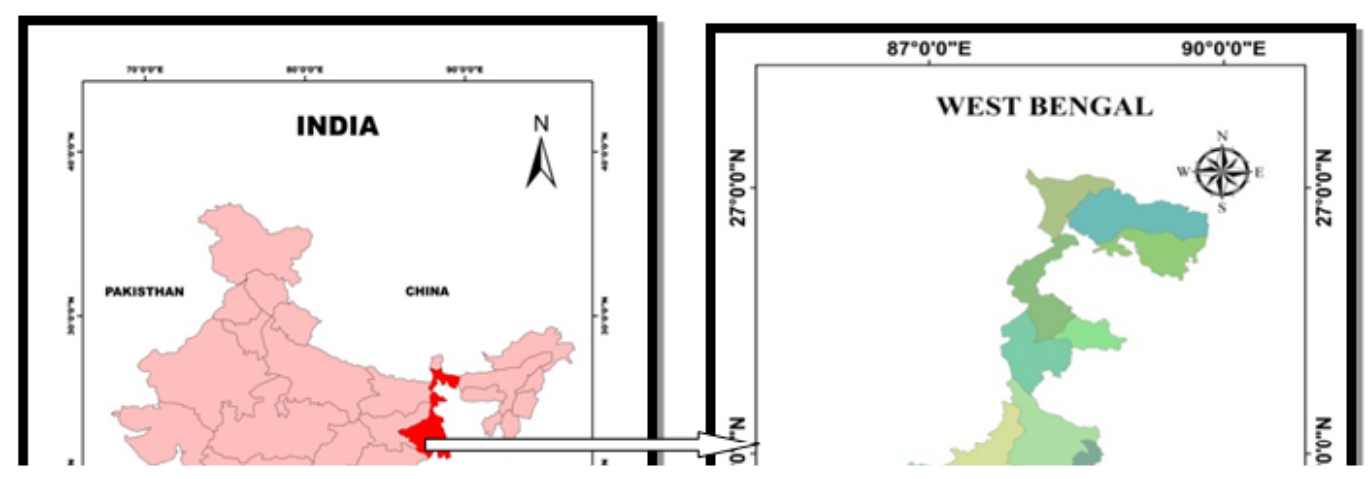




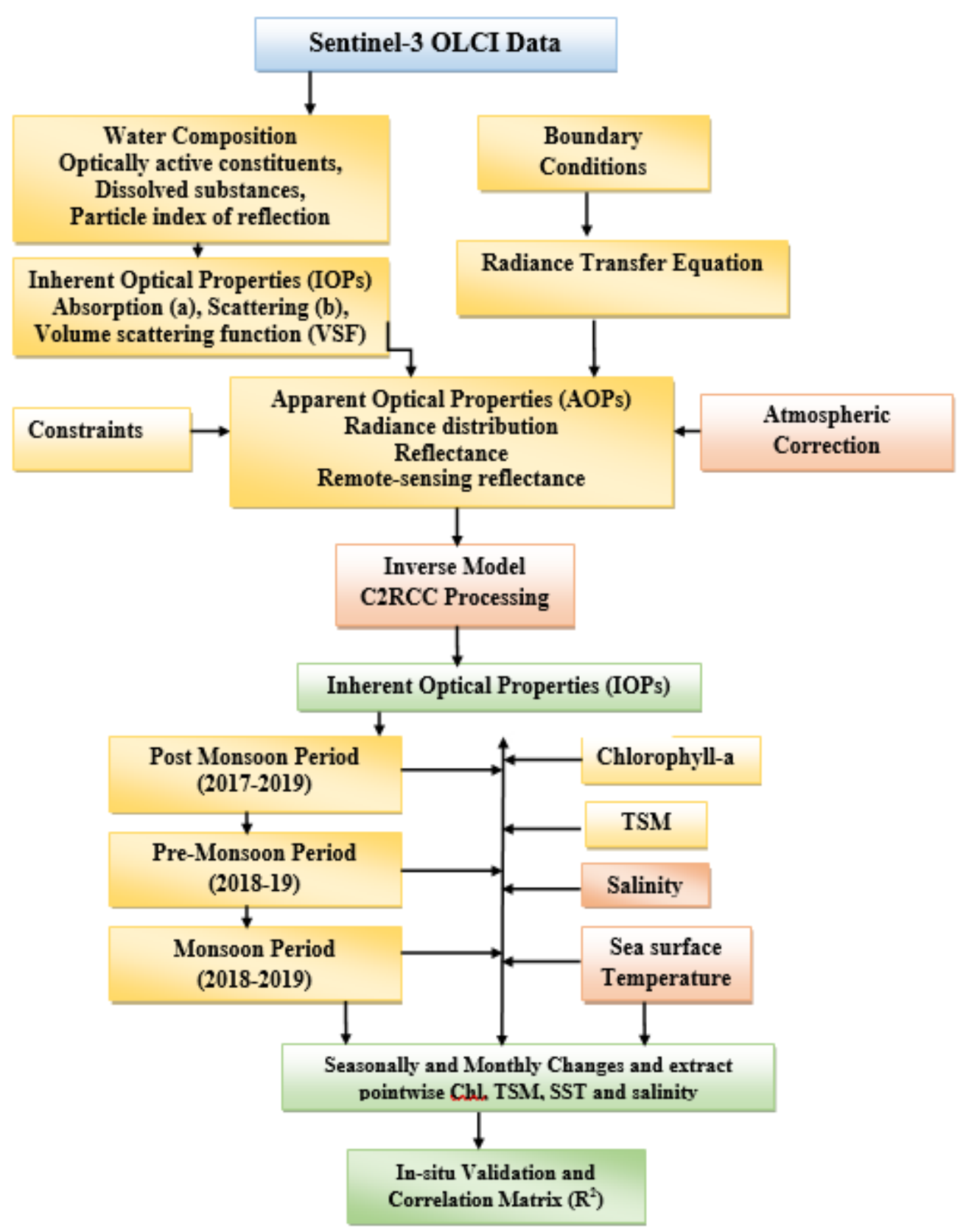

Figure 2

Flowchart showing the Methodology of Water Quality Modelling using Sentinel-3 images 


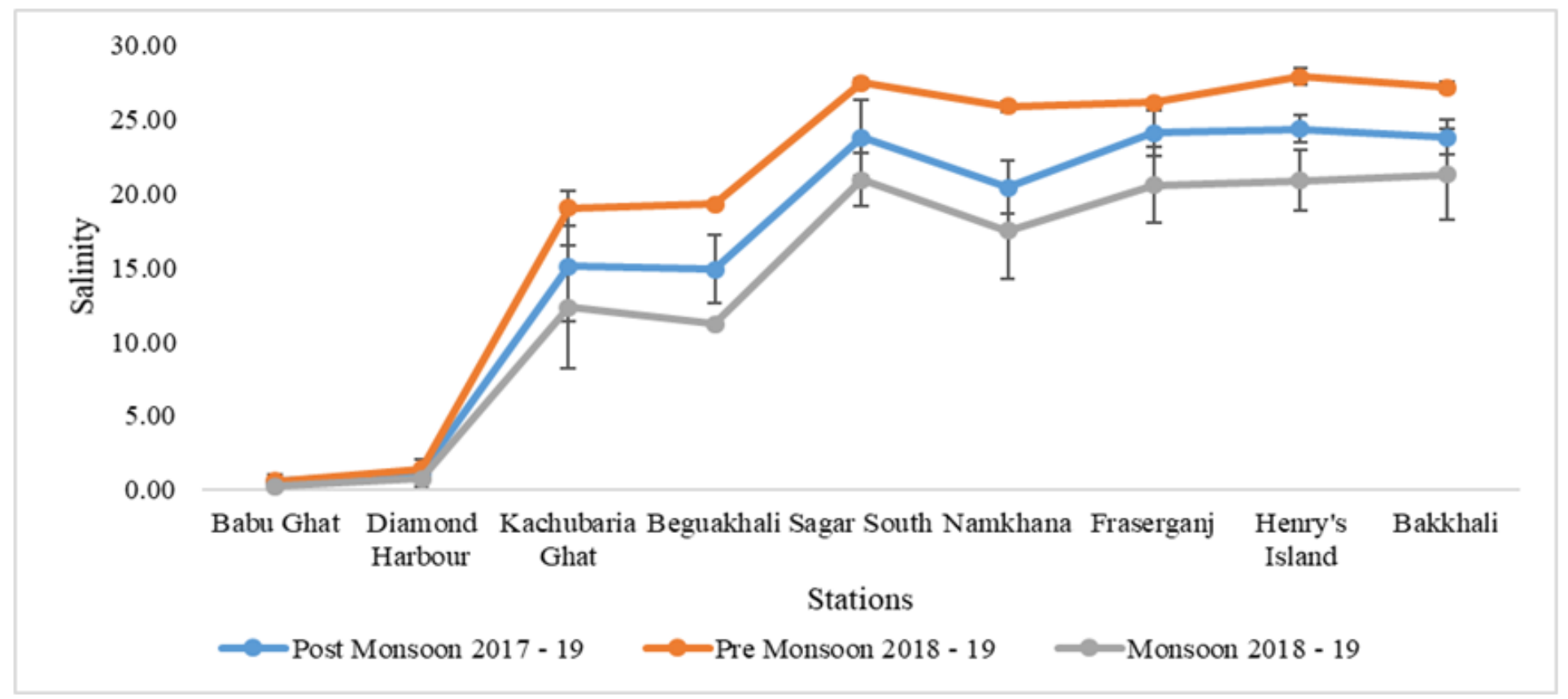

Figure 3

Seasonal Variation of In-situ Salinity at the different stations

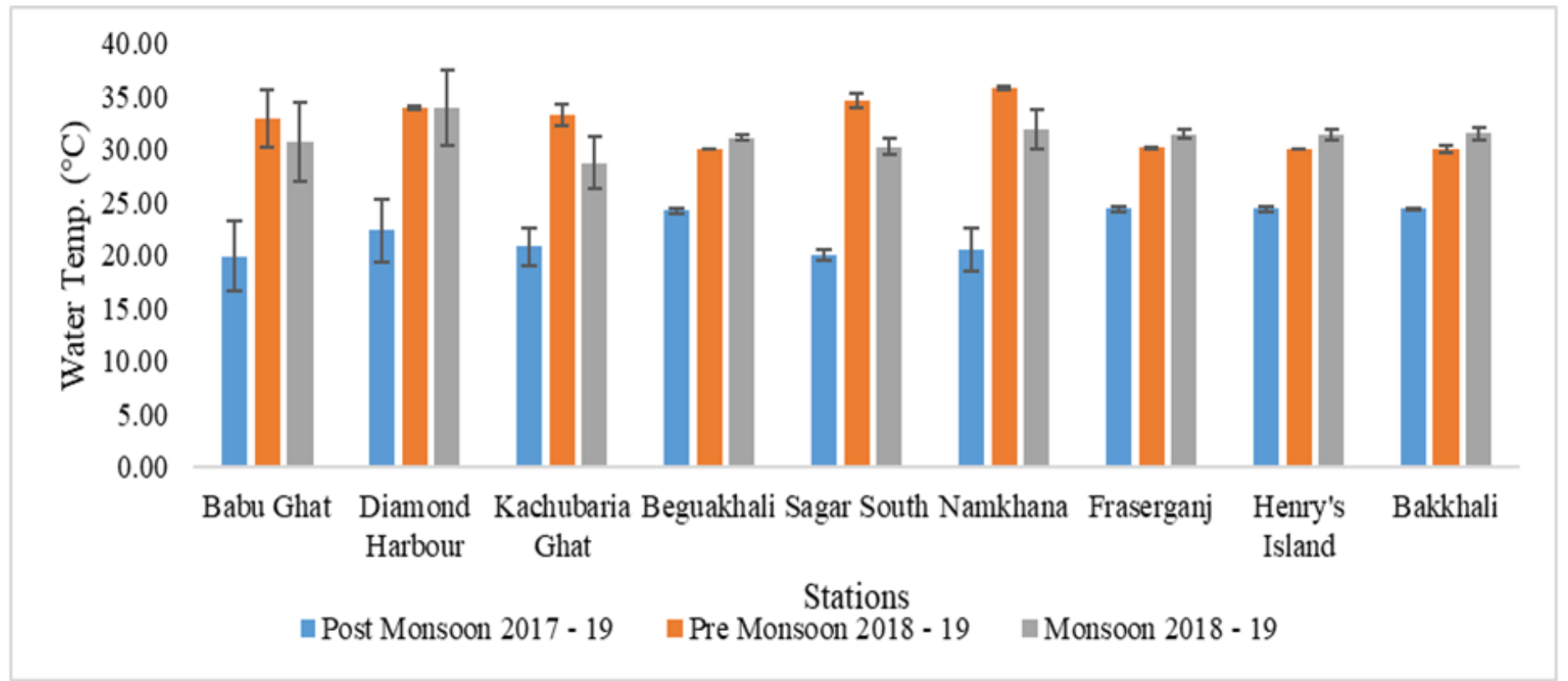

Figure 4

Seasonal Variation of In-situ Water Temperature $\left({ }^{\circ} \mathrm{C}\right)$ in different stations 


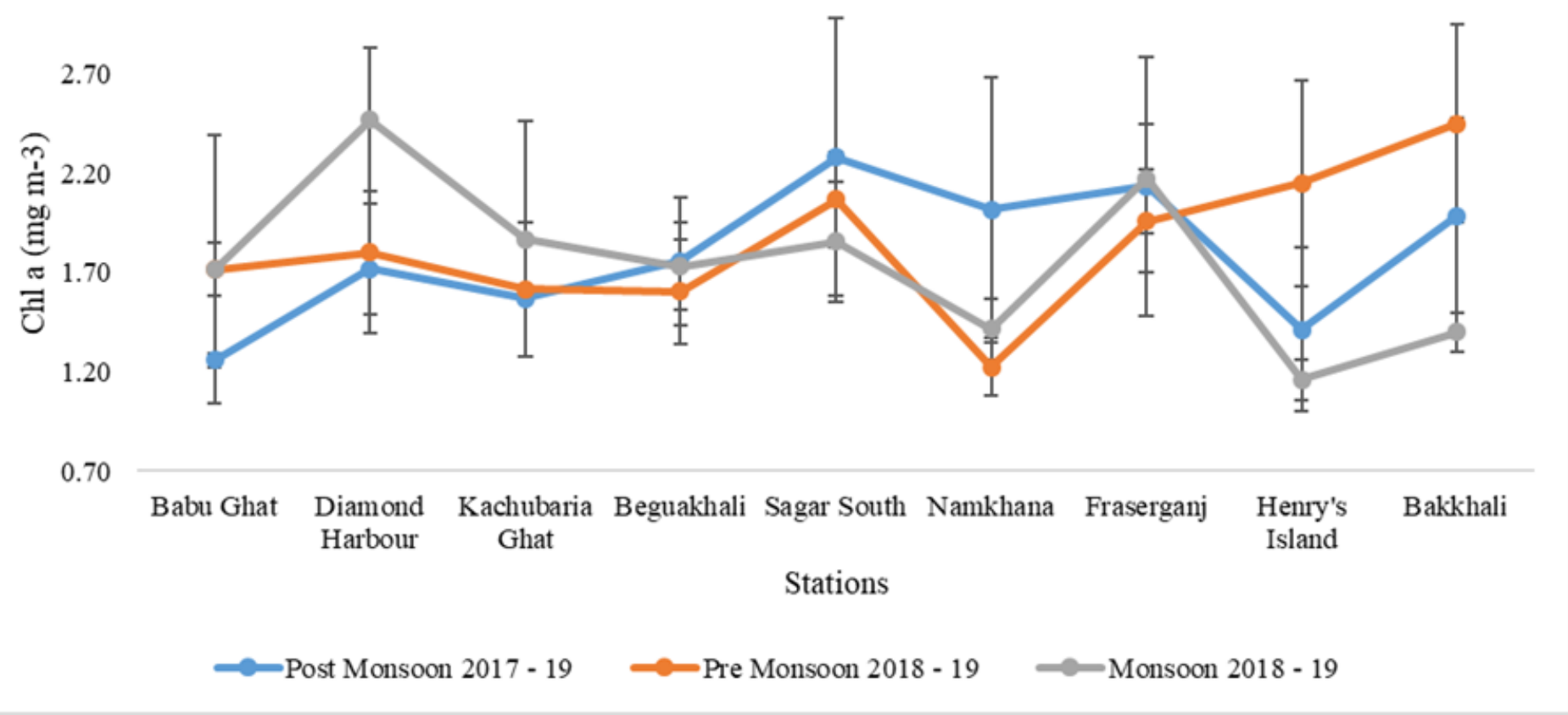

\section{Figure 5}

Seasonal Variation of In-situ Chlorophyll-a $\left(\mathrm{mg} \mathrm{m}^{-3}\right)$ at the different stations

\section{Figure 6}

(a) Chlorophyll-a distribution during the monsoon season (2018 \& 2019).(b) Chlorophyll-a distribution during the post monsoon season $(2017,2018,2019)$.(c) Map showing the distributions of Chlorophyll-a during the post monsoon season $(2018 \& 2019)$

\section{Figure 7}

Seasonal Variation in Weight of TSM $\left(\mathrm{mg} \mathrm{L}^{-1}\right)$ at the In-situ stations

\section{Figure 8}


(a). Map showing distribution of TSM during the Post Monsoon season (2017, 2018 \& 2019).(b). Map showing distribution of TSM during the Pre- Monsoon season (2018 \& 2019). (c). Map showing distribution of TSM during Monsoon (2018 \& 2019)
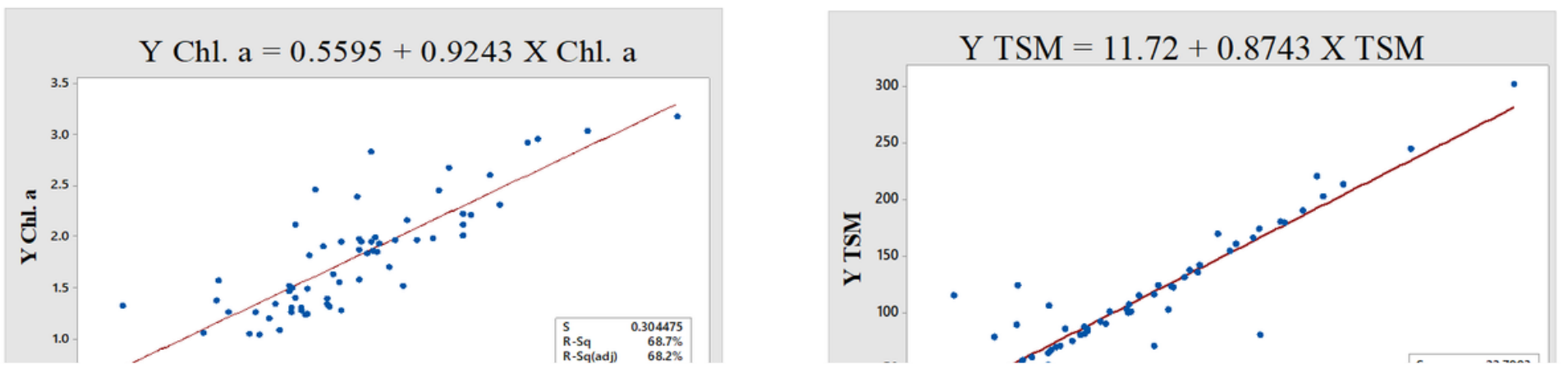

Figure 9

(a). Regression plot for Chlorophyll-a ( $Y$ Chl. a is the in-situ value and $X$ Chl. a is the Sentinel 3 estimated value).(b). Regression plot for TSM (Y TSM a is the in-situ value and X TSM. $a$ is the Estimated value)

\section{Figure 10}

In-situ Measurement of Water Quality Estimation in the Hooghly Estuary 